\title{
The Effect of Zidovudine on Neuropsychiatric Measures in HIV-Infected Men
}

\author{
Jack M. Gorman, M.D., Richard Mayeux, M.D., Yaakov Stern, Ph.D., \\ Janet B.W. Williams, D.S.W., Judith Rabkin, Ph.D., Raymond R. Goetz, Ph.D., \\ and Anke A. Ehrhardt, Ph.D.
}

The authors examined the effects of zidovudine on neuropsychiatric measures, at three assessment points separated by 6 months, in 25 HIV-positive men who took zidovudine for at least 6 months and a comparison group of $25 \mathrm{HIV}$-positive men with similar CD4+ T cell counts who had never taken zidovudine. Zidovudine had no statistically significant effect except for a slight improvement in Global Assessment of Functioning scale score. In this small group of subjects there was little benefit but also little evidence of CNS toxicity from zidovudine.

(Am J Psychiatry 1993; 150:505-507)

$\mathrm{Z}$ idovudine (formerly AZT) is an inhibitor of retroviral reverse transcriptase that has been shown to interfere with cellular infection by HIV. CSF studies have indicated that zidovudine rapidly penetrates the CNS $(1,2)$. Studies have suggested that zidovudine treatment is associated with both improvement in neurological and neuropsychiatric function $(3,4)$ and CNS toxicity (5).

We are currently following a cohort of HIV-seropositive gay and bisexual men who receive their treatment in the community by physicians and clinics of their choice. We recently evaluated the effect of zidovudine on a range of neuropsychiatric measures among members of our cohort during a 1-year period of observation.

\section{METHOD}

We have previously reported on a cohort of $123 \mathrm{HIV}$-seropositive gay and bisexual men recruited in 1987 for a longitudinal study (6, 7). The men are seen every 6 months for a comprehensive evaluation that includes demographic information, medical history and physical examination, lymphocyte subset analysis, neurological examination, neuropsychological tests, psychiatric assessment, and a zidovudine blood level if the subject reports taking zidovudine. We identified 30 HIV subjects from this cohort who had detectable blood levels for

Received Jan. 27, 1992; revision received June 25, 1992; accepted July 27,1992 . From the HIV Center for Clinical and Behavioral Studies, New York State Psychiatric Institute; and the Departments of Psychiatry and Neurology, College of Physicians and Surgeons, Columbia University, New York. Address reprint requests to Dr. Gorman, New York State Psychiatric Institute, 722 West 168th St., New York, NY 10032.

Supported in part by NIMH grants MH-43620 and MH-30606 and NIMH Research Scientist Development Award MH-00416 (Dr. Gorman).

The authors thank George Todak, M.S.W., for directing the project and Ronda Friedman, R.N., for taking medical histories and obtaining blood samples.

Copyright (C) 1993 American Psychiatric Association. zidovudine at two or more consecutive 6-month assessments. We chose the evaluation done 6 months before the first positive zidovudine blood level to represent baseline (pre-zidovudine). For each of these 30 men we then attempted to select a seropositive man from the same cohort who denied ever taking zidovudine and had a CD4+ T cell count within $40 \mathrm{cell} s / \mathrm{mm}^{3}$ of a corresponding zidovudine-treated subject's baseline cell count. We were able to find 25 such HIV-positive, zidovudine-untreated men who met these criteria. The five zidovudine-treated subjects for whom we could not find a suitable comparison subject all had CD4+ counts less than $130 \mathrm{cells} / \mathrm{mm}^{3}$. We chose to select a zidovudine-untreated comparison group on the basis of CD4+ T cell number because this is widely believed to be the most accurate marker of HIV disease progression.

We then performed a two-way repeated measures analysis of variance (ANOVA) with the zidovudine-treated and -untreated groups as the between-subjects factor and three time points covering three consecutive 6-month evaluations (including baseline for the zidovudinetreated group) as the within-subjects (repeated measure) factor on the following measures: 1) Hamilton Rating Scale for Depression score, 2) Hamilton Rating Scale for Anxiety score, 3) Global Assessment of Functioning scale score, 4) a modification of the Kurtzke Scale, described elsewhere (8), that measures degree of neurological involvement from HIV infection, and 5) two global measures of performance on a battery of neuropsychological tests-the global performance rating and the neuropsychologist's impression-that were developed by our group specifically for work with HIV-infected patients and are also described in detail elsewhere (8). In some cases a complete series of these assessments was not available or collected, and as a result the number of comparable pairs of subjects varies. Significance level for the repeated measures ANOVAs was set at 0.05 , but if the Mauchly sphericity test was significant, Greenhouse-Geisser-corrected degrees of freedom and probability levels were calculated as a conservative test. All subjects signed informed consent forms before participating in any research procedures.

\section{RESULTS}

At the first assessment under consideration herepre-zidovudine for the group that took zidovudine-the mean CD4 + T cell count for the zidovudine-treated group was 302 cells $/ \mathrm{mm}^{3}$ and for the zidovudine-untreated group, it was 300 cells $/ \mathrm{mm}^{3}$. For the zidovu- 
dine-treated group, $28 \%(\mathrm{~N}=7$ of 25$)$ were in CDC stage II at the pre-zidovudine visit, $32 \%(\mathrm{~N}=8)$ were in CDC stage III, and $40 \%(\mathrm{~N}=10)$ were in CDC stage IV. The corresponding stages for the zidovudine-untreated group were $32 \%(\mathrm{~N}=8$ of 25$)$ in stage II, $16 \%(\mathrm{~N}=4)$ in stage III, and $52 \%(\mathrm{~N}=13)$ in stage IV. The distribution of CDC stages in the two groups was not statistically different. The mean dose of zidovudine for the treated group was $591 \mathrm{mg} /$ day ( $\mathrm{SD}=271$, range $=200-1200$ ). This represents a moderate dose of zidovudine. In general, mean scores for all of the neuropsychiatric measures were in the unimpaired range (data available upon request from Dr. Gorman).

The repeated measures ANOVAs revealed a significant group difference for the neuropsychologist's impression score ( $\mathrm{F}=6.54, \mathrm{df}=1,46, \mathrm{~N}=24$ pairs, $\mathrm{p}=0.01$ ), with the mean score slightly worse at each of the three time points in the zidovudine-treated group. There were no significant group effects for the Hamilton depression scale, the Hamilton anxiety scale, Global Assessment of Functioning scale, Kurtzke, or global performance rating scores. There were significant time effects for both global performance rating $(\mathrm{F}=3.50, \mathrm{df}=2,92, \mathrm{~N}=24$ pairs, $\mathrm{p}=0.03$ ) and neuropsychologist's impression $(\mathrm{F}=$ $3.62, \mathrm{df}=2,92, \mathrm{~N}=24$ pairs, $\mathrm{p}=0.03$ ) scores. In both cases there was a slight improvement in neuropsychological performance at the second assessment, but scores generally returned to baseline at the third assessment. The time effect was not statistically significant for any of the other measures. Only the Global Assessment of Functioning scale score showed a significant Group by Time interaction $(\mathrm{F}=3.74, \mathrm{df}=2,84, \mathrm{~N}=22$ pairs, $\mathrm{p}=$ 0.03 ). The zidovudine-treated group showed a small improvement in Global Assessment of Functioning scale score, while the zidovudine-untreated group showed a small decline.

\section{DISCUSSION}

In a small group of subjects we were unable to detect substantial benefit from zidovudine therapy on neurological, neuropsychological, and psychiatric measures over a 1-year period of observation. On the other hand, there was also no evidence of neuropsychiatric toxicity from zidovudine.

Several important limitations need to be emphasized in evaluating these observations. This was not a controlled trial of zidovudine use, but rather a naturalistic study. Patients were treated by their own clinicians, who varied widely in their expertise and familiarity with HIV infection and antiretroviral therapy. Furthermore, although we believe it highly unlikely, we cannot be absolutely certain that subjects who denied taking zidovudine were not, in fact, actually taking the drug. We did not obtain blood for zidovudine levels on all subjects, only subjects who reported zidovudine use.

It should also be noted that mean scores on all of the neuropsychiatric measures were in the relatively unimpaired range. It is likely, therefore, that given the lack of overall serious neuropsychiatric impairment, we are limited in the ability to show a positive effect of zidovudine treatment. We have more confidence at present in our ability to show a lack of deteriorative effect of zidovudine on neuropsychiatric status than to show an ameliorative effect.

Our findings are at variance with respect to neuropsychiatric measures from those of Yarchoan et al. (3) and Schmitt et al. (4). Yarchoan et al. reported that zidovudine improved memory, motor function, general cognitive ability, nerve conduction studies, and findings on positron emission tomography in three of four patients, but there was no control group. Schmitt et al., with a relatively large sample size and under doubleblind, placebo-controlled conditions, showed that zidovudine improved attention, memory, visual-motor, and simple-motor performance among patients with AIDS. It should be noted, however, that patients with AIDSrelated complex demonstrated much less improvement with zidovudine therapy in these areas and the report covered only 16 weeks of treatment. Hence, it is possible that zidovudine will improve CNS function only in patients with very advanced HIV infection and only for short periods of time. Consistent with our results are two more recent reports that failed to find any beneficial effects of zidovudine on neurophysiological (9) and neuropsychological (10) performance.

Although zidovudine may increase CD4 $+\mathrm{T}$ cells in HIV-infected patients, it remains unclear to what degree it improves quality of life or improves neuropsychiatric function. We hope that this report will prompt other investigators to examine the effects of zidovudine on behavioral and CNS measures in larger samples so that a more complete picture emerges of the benefits to be derived from zidovudine therapy.

\section{REFERENCES}

1. Collins JM, Unadkat JD: Clinical pharmacokinetics of zidovudine: an overview of current data. Clin Pharmacokinet 1989; 17:1-9

2. Klecker RW Jr, Collins JM, Yarchoan R, Thomas R, Jenkins JF, Broder S, Myers CE: Plasma and cerebrospinal fluid pharmacokinetics of 3'-azido-3'-deoxythymidine: a novel pyrimidine analog with potential applications for the treatment of patients with AIDS and related diseases. Clin Pharmacol Ther 1987; 41 : 407-412

3. Yarchoan R, Berg G, Brouwers P, Fischl MA, Spitzer AR, Wichman A, Grafman J, Thomas RV, Safai B, Brunetti A, Perno CF, Schmidt PJ, Larson SM, Myers CE, Broder S: Response of human-immunodeficiency-virus-associated neurological disease to 3'-azido-3'-deoxythymidine. Lancet 1987; 1:132-135

4. Schmitt FA, Digley JW, McKinnis R, Logue PE, Evans RW, Drucker JL: Neuropsychological outcome of zidovudine (AZT): treatment of patients with AIDS and AIDS-related complex. N Engl J Med 1988; 319:1573-1578

5. Artigas J, Arastech K, Averdunk R, Bachler B, Hornscheidt M, Grosse G, Lage M, Niedobitek F: Hyaline gobules reacting positively with zidovudine antibody in brain and spinal cord of AIDS patients. Lancet 1991; 337:1127-1128

6. Gorman JM, Kertzner R, Todak G, Goetz RR, Williams JBW, Rabkin J, Meyer-Bahlburg HFL, Mayeux R, Stern Y, Lange M, Dobkin J: Multidisciplinary baseline assessment of homosexual men with and without human immunodeficiency virus infec- 
tion, I: overview of study design. Arch Gen Psychiatry 1991; 48: 120-123

7. Gorman JM, Kertzner R, Cooper T, Goetz RR, Lagomasino I, Novacenko H, Williams JBW, Stern Y, Mayeux R, Ehrhardt AA: Glucocorticoid level and neuropsychiatric symptoms in homosexual men with HIV infection. Am J Psychiatry 1991; 148:41-45

8. Stern Y, Marder K, Bell K, Chen J, Dooneief G, Goldstein S, Mindry D, Richards M, Sano M, Williams J, Gorman J, Ehrhardt A, Mayeux R: Multidisciplinary baseline assessment of homosexual men with and without human immunodeficiency virus infection, III: neurologic and neuropsychological findings. Arch Gen Psychiatry 1991; 48:131-138

9. Koralnik IJ, Burkhard P, Ruiz-Scrignari V, Mayer E, Vibert D, Volanschi M, Hirschel B: Effect of zidovudine (ZID) on early neurological manifestations of HIV infection, in Abstracts, VIl International Conference on AIDS. Los Angeles, American Foundation for AIDS Research, 1991

10. Kocsis A, Winwood MA, Hopper C, Peters B, Pinching A, Hay P, Goldmeier D: Evaluation of the effects of zidovudine and amoxil on neuropsychological functioning and mood. Ibid 